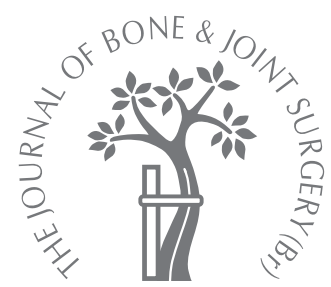

\title{
A comparison of regional and general anaesthesia for total replacement of the hip or knee
}

\author{
A META-ANALYSIS
}

S. $\mathrm{Hu}$,

Z.-Y. Zhang,

Y.-Q. Hua,

J. Li,

Z.-D. Cai

From the Second

Military Medical

University, Shanghai,

People's Republic of

China
S. Hu, MD, Orthopaedic

Surgeon

Z.-Y. Zhang, MD, Professor

Y.-O. Hua, MD, Orthopaedic

Surgeon

J. Li, MD, Orthopaedic

Surgeon

Z.-D. Cai, MD, Professor

Department of Orthopaedics

Changhai Hospital, Second

Military Medical University,

168 Changhai Road, Shanghai

200433, People's Republic of

China.

Correspondence should be sent to Professor Z.-D. Cai; e-mail:

zhengdongcai1961@yahoo.cn

(C)2009 British Editorial Society of Bone and Joint Surgery doi:10.1302/0301-620X.91B7. $21538 \$ 2.00$

J Bone Joint Surg [Br] 2009;91-B:935-42.

Received 16 July 2008;

Accepted after revision 12

March 2009

\begin{abstract}
We performed a meta-analysis to evaluate the relative efficacy of regional and general anaesthesia in patients undergoing total hip or knee replacement. A comprehensive search for relevant studies was performed in PubMed (1966 to April 2008), EMBASE (1969 to April 2008) and the Cochrane Library. Only randomised studies comparing regional and general anaesthesia for total hip or knee replacement were included.

We identified 21 independent, randomised clinical trials. A random-effects model was used to calculate all effect sizes. Pooled results from these trials showed that regional anaesthesia reduces the operating time (odds ratio (OR) $-0.19 ; 95 \%$ confidence interval (Cl) -0.33 to -0.05 ), the need for transfusion (OR $0.45 ; 95 \% \mathrm{Cl} 0.22$ to 0.94 ) and the incidence of thromboembolic disease (deep-vein thrombosis OR $0.45,95 \% \mathrm{Cl} 0.24$ to 0.84 ; pulmonary embolism OR $0.46,95 \% \mathrm{Cl} 0.29$ to 0.80 ).

Regional anaesthesia therefore seems to improve the outcome of patients undergoing total hip or knee replacement.
\end{abstract}

In 2005, more than 375000 patients underwent total hip replacement (THR) and more than 530 000 had total knee replacement (TKR) in the United States. ${ }^{1}$ Despite the frequency with which these procedures are carried out, there remains controversy as to whether they are best performed under regional anaesthesia using epidural or spinal neuraxial blockade, or general anaesthesia. In 2000, Rodgers et $\mathrm{al}^{2}$ published a meta-analysis which addressed the clinical merits of neuraxial blockade for a variety of surgical procedures. However, its place in patients undergoing joint replacement remains uncertain.

Regional anaesthesia in total joint replacement is claimed to decrease the incidence of deep-vein thrombosis (DVT) and pulmonary embolism and to reduce intraoperative bleeding, the need for transfusion and the length of hospital stay. ${ }^{3-9}$ It can also increase patient satisfaction especially after one-stage bilateral THR or TKR. ${ }^{10}$ Epidural anaesthesia combined with post-operative epidural analgesia can reduce the physiological stress of surgery and the incidence of complications as well as improving the overall outcome of surgery. ${ }^{11}$ However, other studies have reported contradictory results. ${ }^{12-14}$ Moiniche et $\mathrm{al}^{15}$ have shown that there may not be any advantage in regional techniques. Moreover, spinal and epidural anaesthesia and analgesia may cause hypotension, motor blockade, urinary retention and pruritus. ${ }^{16}$ Although there have been many refinements to reduce such complications, there is still the potential for inadvertent dural puncture and neurological injury which may make these techniques less acceptable. ${ }^{11}$ In addition, many of these studies have been compromised by small numbers of patients and, in some cases, the relatively rare occurrence of complications. Consequently, it has been difficult to draw any conclusions about the effect of the choice of anaesthesia on the outcome of joint replacement.

We carried out a meta-analysis to evaluate the relative efficacy of regional and general anaesthesia in patients undergoing joint replacement. We concentrated on THR and TKR and restricted the regional techniques to epidural or spinal approaches, to limit the number of confounding variables.

\section{Materials and Methods}

A search of the literature was undertaken using PubMed (1966 to April 2008), EMBASE (1969 to April 2008) and the Cochrane Library databases using the following keywords: hip replacement, hip arthroplasty, knee replacement, knee arthroplasty, regional anaesthesia, epidural anaesthesia, spinal anaesthesia and general anaesthesia. The terms regional, epidural, spinal and general anaesthesia were 
Table I. Characteristics of the randomised controlled trials of regional versus general anaesthesia in total joint replacement of the lower limb contributing data to our meta-analysis

\begin{tabular}{|c|c|c|c|}
\hline Source & Joint studied ${ }^{*}$ & Regional anaesthesia technique & Outcomes studied $^{\dagger}$ \\
\hline Modig et $\mathrm{al}^{3}$ & THR & Continuous epidural & Duration of surgery, blood loss, DVT, PE \\
\hline Modig et $\mathrm{al}^{4}$ & THR & Continuous epidural & Duration of surgery, blood loss, DVT, PE \\
\hline Modig et $\mathrm{al}^{5}$ & THR & Continuous epidural & Duration of surgery, blood loss, DVT, PE \\
\hline Davis et al $^{6 \ddagger}$ & THR & Spinal & $\begin{array}{l}\text { Duration of surgery, blood loss, number of } \\
\text { patients transfused, DVT, PE }\end{array}$ \\
\hline Jørgensen et $a l^{8}$ & TKR & Continuous epidural & DVT, PE \\
\hline Nielsen et $\mathrm{al}^{9}$ & TKR & Continuous epidural & DVT \\
\hline Brueckner et al ${ }^{12}$ & THR & Spinal & Duration of surgery, blood loss \\
\hline Planes et al $^{13}$ & THR & Spinal & Duration of surgery, blood loss, DVT \\
\hline Mitchell et al ${ }^{14}$ & TKR & Continuous epidural & DVT \\
\hline Borghi et $\mathrm{al}^{21 \neq}$ & THR & Continuous epidural & $\begin{array}{l}\text { Duration of surgery, blood loss, number of } \\
\text { patients transfused }\end{array}$ \\
\hline Gonano et $\mathrm{al}^{24}$ & THR or TKR & Spinal & Duration of surgery \\
\hline Lattermann et $\mathrm{al}^{25}$ & THR & Combined spinal and epidural & Duration of surgery, blood loss \\
\hline Kita et $\mathrm{al}^{26}$ & THR & Continuous epidural & $\begin{array}{l}\text { Duration of surgery, blood loss, length of } \\
\text { hospital stay }\end{array}$ \\
\hline Kudoh et $\mathrm{al}^{27}$ & TKR & Spinal & Duration of surgery, blood loss, PONV \\
\hline Modig and Karlstrom ${ }^{28}$ & THR & Continuous epidural & Duration of surgery, blood loss \\
\hline Wulf et $\mathrm{al}^{29}$ & THR & Continuous epidural & Duration of surgery, length of hospital stay \\
\hline Donatelli et $\mathrm{al}^{30}$ & THR or TKR & Continuous epidural & $\begin{array}{l}\text { Duration of surgery, blood loss, number of } \\
\text { patients transfused }\end{array}$ \\
\hline Hole et $\mathrm{al}^{31}$ & THR & Single-injection epidural & Duration of surgery, PE \\
\hline Jones et $\mathrm{al}^{32}$ & THR or TKR & Spinal & $\begin{array}{l}\text { Duration of surgery, number of patients trans- } \\
\text { fused, length of hospital stay, DVT, PE mortality }\end{array}$ \\
\hline Williams-Russo et $a^{33}$ & TKR & Continuous epidural & Duration of surgery, blood loss, DVT, PE \\
\hline Keith $^{34}$ & THR & Single-injection epidural & Blood loss, number of patients transfused \\
\hline
\end{tabular}

linked with 'or' and combined using 'and' with each subsequent term. Each publication was independently reviewed by two authors (SH, Z-DC) and the data collected entered onto a standard sheet. We limited the search to articles published in English. Only randomised, controlled trials which compared the outcome of elective THR and TKR carried out under regional anaesthesia with those carried out under general anaesthesia were included. We included all of these despite the fact that some did not address all the aspects that we wished to study. Nonetheless, we read all the original articles carefully and extracted relevant data in order to decrease publication bias. We also checked the references of each article for other studies which met all our inclusion criteria. We extracted the following outcome data from each study if reported: the operating time, the intraoperative blood loss, the number of patients requiring blood transfusion, the number of patients with DVT or pulmonary embolism, diagnosed radiologically or clinically, the length of hospital stay and any deaths.

The data collection was not blinded. A third reviewer (Z-YZ) compared the two sets of data collection sheets and any differences were resolved by discussion and reconfirming the data from the original paper. We attempted to contact the authors of a trial if they had published more than one report on the subject to confirm that the data in each of their publications were from different groups of patients.
Lastly, we asked authors if they knew of any other relevant published studies.

Statistical analysis. We only included those outcome parameters which were presented in numerical format. Continuous outcome parameters were expressed as the mean and SD and dichotomous outcomes as the number of events. The level of significance for all tests was set at a two-sided p-value of 0.05 and variances were not assumed to be equal. Patients who had a general anaesthetic were treated as a control group, and those with regional anaesthesia as an intervention group. The odds ratios (OR) and the $95 \%$ confidence interval (CI) were calculated for dichotomous outcomes. The standardised mean difference and the $95 \%$ CI were presented for continuous outcomes. Heterogeneity among studies was tested using the chisquared test. We used a random-effects model to calculate all effect sizes since it was more conservative and included both the random variation within the studies and the variation among the different studies. Moreover, the pooled estimates calculated by the random-effects and fixed-effects models were similar when there was minimal heterogeneity between studies. Whenever possible, subgroup analyses were performed to detect and evaluate clinically significant differences. All statistical analyses were performed using the freeware program Review Manager 4.2 (Cochrane Collaboration, Oxford, United Kingdom). 
Table II. Results of the meta-analysis for all the outcomes of total joint replacement

\begin{tabular}{|c|c|c|c|c|c|c|c|}
\hline \multirow[b]{2}{*}{ Outcome $^{*}$} & \multirow[b]{2}{*}{ Number of studies } & \multirow[b]{2}{*}{ SMD or OR $(95 \% \mathrm{CI})^{\dagger}$} & \multirow[b]{2}{*}{ Z-value } & \multirow[b]{2}{*}{ p-value } & \multicolumn{3}{|l|}{ Heterogeneity } \\
\hline & & & & & Chi-squared test & p-value & $\mathrm{I}^{2}(\%)^{\ddagger}$ \\
\hline Duration of surgery & 17 & SMD $-0.12(-0.23$ to -0.02$)$ & 2.36 & 0.02 & 13.99 & 0.60 & 0.0 \\
\hline Intra-operative blood loss & 12 & SMD $-0.50(-0.96$ to -0.04$)$ & 2.12 & 0.03 & 107.04 & $<0.0001$ & 91.6 \\
\hline Length of hospital stay & 3 & SMD $-0.55(-2.47$ to +1.37$)$ & 0.57 & 0.57 & 4.31 & 0.12 & 53.6 \\
\hline Number of transfusions & 5 & OR 0.45 (0.22 to 0.94$)$ & 2.14 & 0.03 & 8.94 & 0.06 & 55.3 \\
\hline DVT & 10 & OR 0.45 (0.24 to 0.84$)$ & 2.48 & 0.01 & 28.88 & 0.0007 & 68.8 \\
\hline PE & 8 & OR 0.46 (0.21 to 1.02$)$ & 1.9 & 0.06 & 11.85 & 0.11 & 10.9 \\
\hline PONV & 2 & OR 0.27 (0.11 to 0.64$)$ & 2.96 & 0.003 & 0.19 & 0.66 & 0.0 \\
\hline Mortality & 2 & OR 0.94 (0.14 to 6.52$)$ & 0.06 & 0.95 & 0.83 & 0.36 & 0.0 \\
\hline
\end{tabular}

* DVT, deep-vein thrombosis; PE, pulmonary embolism; PONV, post-operative nausea and vomiting

† SMD, standardised mean difference; OR, odds ratio; $95 \% \mathrm{Cl}, 95 \%$ confidence interval

$¥$ inconsistency value, this represents the extent of the heterogeneity

Table III. Subgroup analysis of some of the outcome assessments

\begin{tabular}{|c|c|c|c|c|c|c|c|c|}
\hline \multirow[b]{2}{*}{ Outcome $^{*}$} & \multirow[b]{2}{*}{ Subgroup $^{\dagger}$} & \multirow[b]{2}{*}{ Number of studies } & \multirow[b]{2}{*}{ SMD or OR $(95 \% \mathrm{Cl})^{\ddagger}$} & \multirow[b]{2}{*}{ Z-value } & \multirow[b]{2}{*}{ p-value } & \multicolumn{3}{|l|}{ Heterogeneity } \\
\hline & & & & & & Chi-squared test & p-value & $I^{2}(\%)^{\S}$ \\
\hline \multirow[t]{2}{*}{ Duration of surgery } & THR & 12 & SMD $-0.19(-0.33$ to -0.05$)$ & 2.69 & 0.007 & 9.57 & 0.57 & 0.0 \\
\hline & TKR & 2 & SMD $-0.02(-0.21$ to +0.17 & 0.21 & 0.84 & 0.92 & 0.34 & 0.0 \\
\hline \multirow[t]{2}{*}{ Intra-operative blood loss } & THR & 10 & SMD $-0.65(-1.24$ to -0.06$)$ & 2.16 & 0.03 & 103.24 & $<0.0001$ & 91.3 \\
\hline & THR & 8 & SMD $-0.48(-1.13$ to 0.17$)$ & 1.44 & 0.15 & 82.8 & $<0.0001$ & 91.6 \\
\hline \multirow[t]{2}{*}{ Number of transfusions } & THR & 4 & OR 0.35 (0.18 to 0.67 ) & 3.19 & 0.001 & 4.16 & 0.25 & 27.8 \\
\hline & TKR & None & & & & & & \\
\hline \multirow[t]{2}{*}{ DVT } & $\begin{array}{l}\text { No TED drug } \\
\text { prophylaxis }\end{array}$ & 7 & OR 0.27 (0.14 to 0.52 ) & 3.88 & 0.0001 & 11.7 & 0.07 & 48.7 \\
\hline & TED drug prophylaxis & 3 & OR 1.07 (0.58 to 1.97 ) & 0.21 & 0.83 & 2.78 & 0.25 & 28.1 \\
\hline \multirow[t]{2}{*}{ PE } & $\begin{array}{l}\text { No TED drug } \\
\text { prophylaxis }\end{array}$ & 6 & OR 0.26 ( 0.13 to 0.52 ) & 3.87 & 0.0001 & 2.2 & 0.82 & 0.0 \\
\hline & TED drug prophylaxis & 2 & OR 1.66 (0.61 to 4.52 ) & 1.0 & 0.32 & 0.70 & 0.40 & 0.0 \\
\hline \multicolumn{9}{|c|}{ * DVT, deep-vein thrombosis; PE, pulmonary embolism } \\
\hline \multicolumn{9}{|c|}{ † THR, total hip replacement; TKR, total knee replacement; TED, thromboembolic disease } \\
\hline \multicolumn{9}{|c|}{ ‡ SMD, standardised mean difference; $\mathrm{OR}$, odds ratio; $95 \% \mathrm{Cl}, 95 \%$ confidence interval } \\
\hline \multicolumn{9}{|c|}{$\S$ inconsistency value, this represents the extent of the heterogeneity } \\
\hline
\end{tabular}

\section{Results}

We identified 25 randomised, controlled trials in the English language in which patients had been randomised to receive either regional or general anaesthesia. Of these, one in which the data were reported as medians and ranges was excluded. ${ }^{17}$ Another three were also excluded. One did not present data in a form which could be included in the review $^{18}$ and the other two included confounding factors, namely peri-operative hypotension and hip trauma. ${ }^{19,20}$ Two studies generated more than one publication each, but were counted only once. ${ }^{6,21-23}$ Finally, 21 studies were included in the review ${ }^{3-6,8,9,12-14,21,24-34}$ (Table I). We assessed the presence of publication bias by examining funnel plots which displayed the studies included in the metaanalysis in a plot of effect size against sample size. Fortunately, they showed no evidence of publication bias for the operating time, intraoperative bleeding, rate of transfusion, and the incidence of DVT and pulmonary embolism.

Whenever possible, we also performed several subgroup analyses on the hips and knees independently and then combined them to provide an overall estimate. The results of the meta-analysis are shown in Tables II and III.

Operating time. Data on the operating time were found in 17 studies with a total of 1483 patients. ${ }^{3-6,12,13,21,24-33}$ There was a decrease in the length of the operating time with regional compared with general anaesthesia (standard mean difference $-0.12 ; 95 \%$ CI -0.23 to -0.021 ; Fig. 1 ). In the subgroup meta-analysis, the operating time for THR under regional anaesthesia was significantly shorter than that under general anaesthesia (OR $-0.19 ; 95 \%$ CI -0.33 to $-0.05)$, but there was no significant difference between the two for TKR (OR -0.02; 95\% CI -0.21 to 0.17; Table III). 


\begin{tabular}{|c|c|c|c|c|c|c|c|c|}
\hline \multirow{2}{*}{$\begin{array}{l}\begin{array}{l}\text { Study } \\
\text { or sub-category }\end{array} \\
\text { Hole et } \mathrm{al}^{31}\end{array}$} & \multirow{2}{*}{$\begin{array}{c}\begin{array}{c}\text { Number of } \\
\text { patients }\end{array} \\
29\end{array}$} & \multirow{2}{*}{$\begin{array}{c}\begin{array}{c}\text { Regional anaesthesia } \\
\text { Mean (SD) }\end{array} \\
190.00(32.00)\end{array}$} & \multirow{2}{*}{$\begin{array}{c}\begin{array}{c}\text { Number of } \\
\text { patients }\end{array} \\
31\end{array}$} & $\begin{array}{l}\text { General anaesthesia } \\
\text { Mean (SD) }\end{array}$ & \multicolumn{2}{|c|}{$\begin{array}{c}\text { Standardised mean difference } \\
\text { (random) } 95 \% \mathrm{Cl}\end{array}$} & \multirow{2}{*}{$\begin{array}{c}\begin{array}{c}\text { Weight } \\
(\%)\end{array} \\
3.94\end{array}$} & \multirow{2}{*}{$\begin{array}{c}\begin{array}{c}\text { Standardised mean difference } \\
\text { (random) }(95 \% \mathrm{Cl})\end{array} \\
-0.52(-1.03 \text { to } 0.00)\end{array}$} \\
\hline & & & & $207.00(33.00)$ & & & & \\
\hline Modig et $\mathrm{al}^{3}$ & 15 & $147.00(28.00)$ & 15 & $161.00(35.00)$ & & & 1.99 & $-0.43(-1.15$ to 0.30$)$ \\
\hline Modig et al ${ }^{4}$ & 30 & $146.00(22.00)$ & 30 & $156.00(26.00)$ & & - & 4.00 & $-0.41(-0.92$ to 0.10$)$ \\
\hline Modig et $\mathrm{al}^{5}$ & 48 & $152.00(25.00)$ & 46 & $150.00(26.00)$ & & $\square$ & 6.39 & $0.08(-0.33$ to 0.48$)$ \\
\hline Modig and Karlstrom ${ }^{28}$ & 14 & $132.00(23.00)$ & 10 & $136.00(30.00)$ & & & 1.58 & $-0.15(-0.96$ to 0.66$)$ \\
\hline Davis et $\mathrm{ll}^{6}$ & 69 & $73.00(13.00)$ & 71 & $79.00(21.00)$ & & & 9.39 & $-0.34(-0.67$ to -0.01$)$ \\
\hline Jones et $\mathrm{al}^{32}$ & 74 & $107.00(24.00)$ & 72 & $112.00(28.00)$ & & - & 9.90 & $-0.19(-0.52$ to 0.13$)$ \\
\hline Planès et al ${ }^{13}$ & 61 & $73.30(2.30)$ & 62 & $73.70(2.40)$ & & & 8.35 & $-0.17(-0.52$ to 0.19$)$ \\
\hline Williams-Russo et al $^{33}$ & 134 & $85.00(33.00)$ & 128 & $88.00(32.00)$ & - & - & 17.82 & $-0.09(-0.33$ to 0.15$)$ \\
\hline Wulf et $\mathrm{al}^{29}$ & 43 & $145.00(45.00)$ & 45 & $136.00(29.00)$ & & & 5.95 & $0.24(-0.18$ to 0.66$)$ \\
\hline Brueckner et al ${ }^{12}$ & 16 & $101.00(23.00)$ & 10 & $113.00(39.00)$ & & & 1.64 & $-0.39(-1.19$ to 0.41$)$ \\
\hline Kudoh et $\mathrm{al}^{27}$ & 75 & $106.70(31.50)$ & 75 & $104.20(11.80)$ & & $\mapsto$ & 10.20 & $0.10(-0.22$ to 0.42$)$ \\
\hline Borghi et al ${ }^{22}$ & 70 & $106.00(29.00)$ & 70 & $112.00(41.00)$ & & — & 9.50 & $-0.17(-0.50$ to 0.16$)$ \\
\hline Lattermann et al ${ }^{25}$ & 7 & $95.00(22.00)$ & 8 & $99.00(26.00)$ & & & 1.01 & $-0.16(-1.17$ to 0.86$)$ \\
\hline Gonano et $\mathrm{al}^{24}$ & 20 & $109.00(26.00)$ & 20 & $111.00(36.00)$ & & & 2.72 & $-0.06(-0.68$ to 0.56$)$ \\
\hline Donatelli et $\mathrm{al}^{30}$ & 30 & $175.00(38.00)$ & 30 & $168.00(40.00)$ & & $\longrightarrow$ & 4.07 & $0.18(-0.33$ to 0.68$)$ \\
\hline Kita et $\mathrm{al}^{26}$ & 16 & $71.00(34.00)$ & 9 & $84.00(34.00)$ & & & 1.54 & $-0.37(-1.19$ to 0.45$)$ \\
\hline Total $(95 \% \mathrm{Cl})$ & 751 & & 732 & & & & 100.00 & $-0.12(-0.23$ to -0.02$)$ \\
\hline \multicolumn{9}{|c|}{ Test for heterogeneity: chi-squared $=13.99, \mathrm{df}=16(\mathrm{p}=0.60), \mathrm{I}^{2}=0 \%$} \\
\hline \\
\hline \multicolumn{9}{|c|}{ Test for overall effect: $Z=2.36(p=0.02)$} \\
\hline & & & & -1. & -0.5 & 0.5 & 1.0 & \\
\hline \multicolumn{9}{|c|}{ Favours regional anaesthesia } \\
\hline
\end{tabular}

Fig. 1

Chart showing comparison of the duration of surgery (mean, SD) between the regional and general anaesthesia groups for patients undergoing total joint replacement.

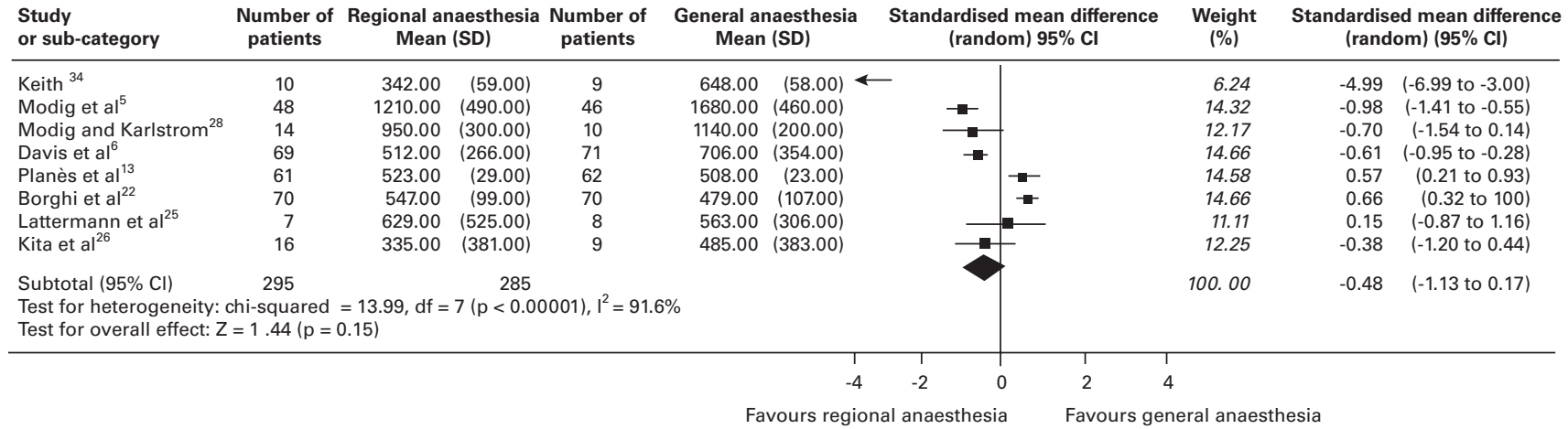

Fig. 2

Chart showing comparison of intraoperative blood loss (mean, SD) between the regional and general anaesthesia groups for patients undergoing total joint replacement.

Intra-operative blood loss. Intraoperative blood loss was reported in 12 studies which included 880 patients. . $^{3-6,13,21,25-28,30,34}$ In five there was no statistical difference in the intraoperative blood loss between regional and general anaesthesia. In another five there was reduced blood loss with regional anaesthesia. The remaining two showed increased blood loss. These differences were statistically significant (standardised mean difference $-0.50,95 \%$ CI -.96 to -0.04 ; Table II).

The pooled data from the ten studies on THR showed a statistically significant decrease in blood loss in patients with regional anaesthesia (standardised mean difference -0.65 ; $95 \%$ CI -1.24 to -0.006 ; Table III).
However, when we excluded two trials in which patients in the regional anaesthesia group had a significantly lower blood pressure than those in the general anaesthesia group, ${ }^{3,4}$ there was no significant difference between the groups (Fig. 2).

Transfusion requirement. Five studies included data on the number of patients transfused intraoperatively. ${ }^{6,21,30,32,34}$ Meta-analysis showed that regional anaesthesia reduced the need for transfusion (OR $0.45 ; 95 \%$ CI 0.22 to 0.94 ; Table II). Subset modelling of the THR group showed that regional anaesthesia reduced the need for transfusion (OR 0.35 ; $95 \%$ CI 0.18 to 0.67 ; Table III). None of the studies presented comparable data for the TKR group and 


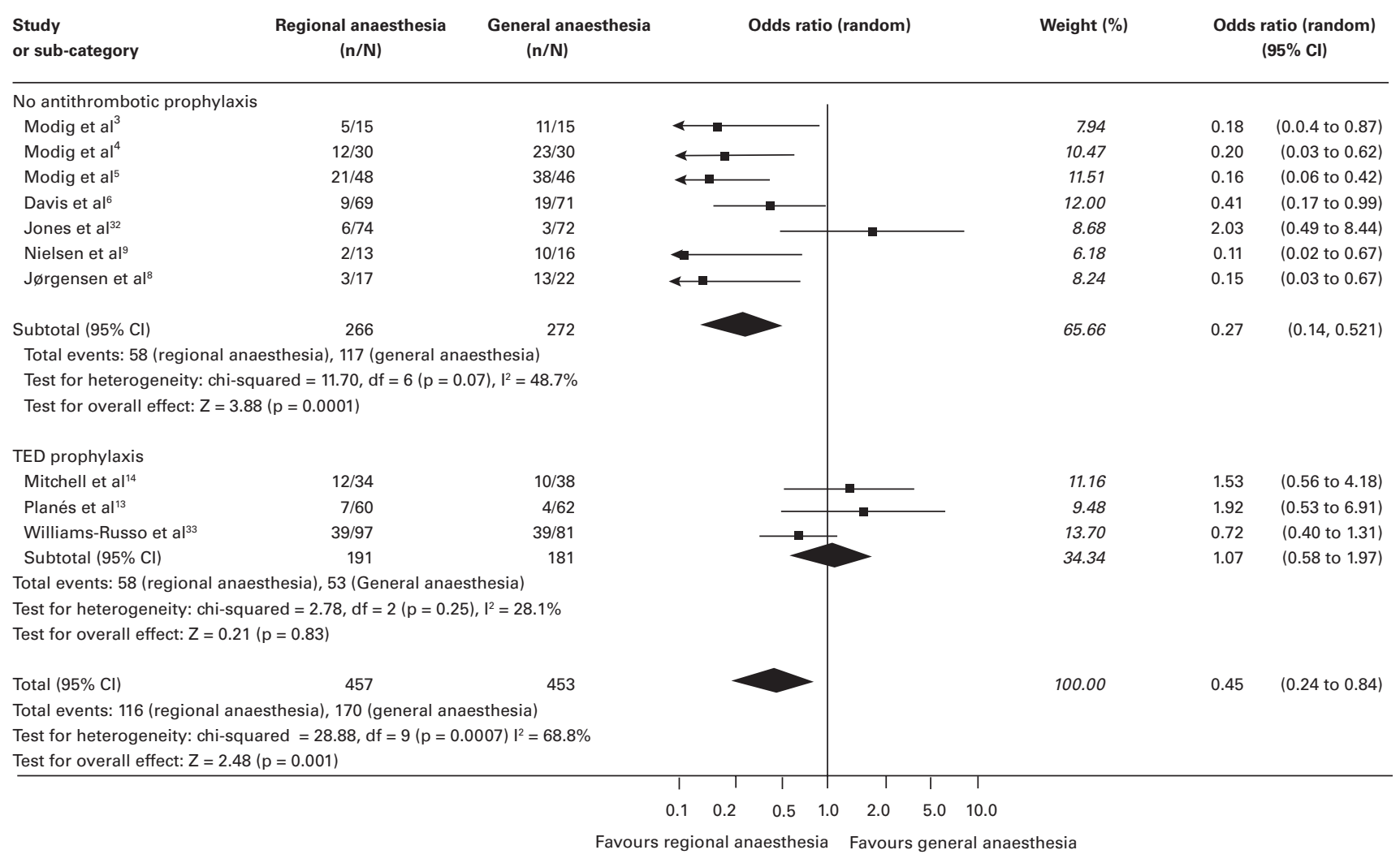

Fig. 3

Chart showing comparison of the number of patients with deep-vein thrombosis in the regional and general anaesthesia groups with and without the administration of thromboembolic disease prophylaxis.

therefore the effect of regional anaesthesia on the need for transfusion in TKR could not be determined.

Thromboembolic disease. Ten studies presented data on the incidence of $\mathrm{DVT}^{3-6,8,9,13,14,32,33}$ and eight on pulmonary embolism..$^{3-6,8,31-33}$ These two meta-analyses showed that regional anaesthesia significantly lowered the incidence of thromboembolic disease when compared with general anaesthesia (DVT 95\% CI 0.24 to 0.84; Fig. 3). Although a random-effects model did not show the difference (pulmonary embolism 95\% CI 0.21 to 1.02 ; Table II), it was identified using a fixed-effects model (pulmonary embolism 95\% CI 0.29 to 0.80; Fig. 4).

However, when subgroup analysis was performed of the studies in which patients had been given anticoagulants, ${ }^{13,14,31,33}$ there was no significant difference in the incidence of thromboembolic disease between the two groups (DVT 95\% CI 0.58 to 1.97; Fig. 3; pulmonary embolism 95\% CI 0.61 to 4.52; Table III).

Post-operative nausea and vomiting. Data on the number of patients who suffered from this were only given in two studies $^{24,27}$ (OR 0.27; 95\% CI 0.11 to 0.64 ; Table II). One noted that regional anaesthesia reduced its incidence, ${ }^{17}$ but pooled data showed significant difference between the two groups.
Other outcome measurements. Data on mortality were presented in only two studies ${ }^{13,32}$ (OR 0.94; 95\% CI 0.14 to 6.52; Table II). There was no obvious difference between regional and general anaesthesia. Meta-analysis was not performed because of insufficient data.

Three studies recorded the length of hospital stay. ${ }^{29,32,33}$ There was no discernible difference between the groups (standardised mean difference $-0.55 ; 95 \%$ CI -2.47 to +1.37; Table II).

\section{Discussion}

Our meta-analysis has shown several potential advantages of regional over general anaesthesia. The former can be beneficial in reducing the duration of surgery, the need for transfusion, post-operative nausea and vomiting and the incidence of thromboembolic disease (DVT and pulmonary embolism) in patients undergoing total joint replacement, particularly THR. There was insufficient evidence to support or refute the use of regional anaesthesia in decreasing intraoperative blood loss, mortality or length of hospital stay.

Duration of surgery refers to the operating time and not to the duration of anaesthesia or recovery. Our metaanalysis has shown that regional anaesthesia had only a minimal effect in reducing the operating time. Sub-group 


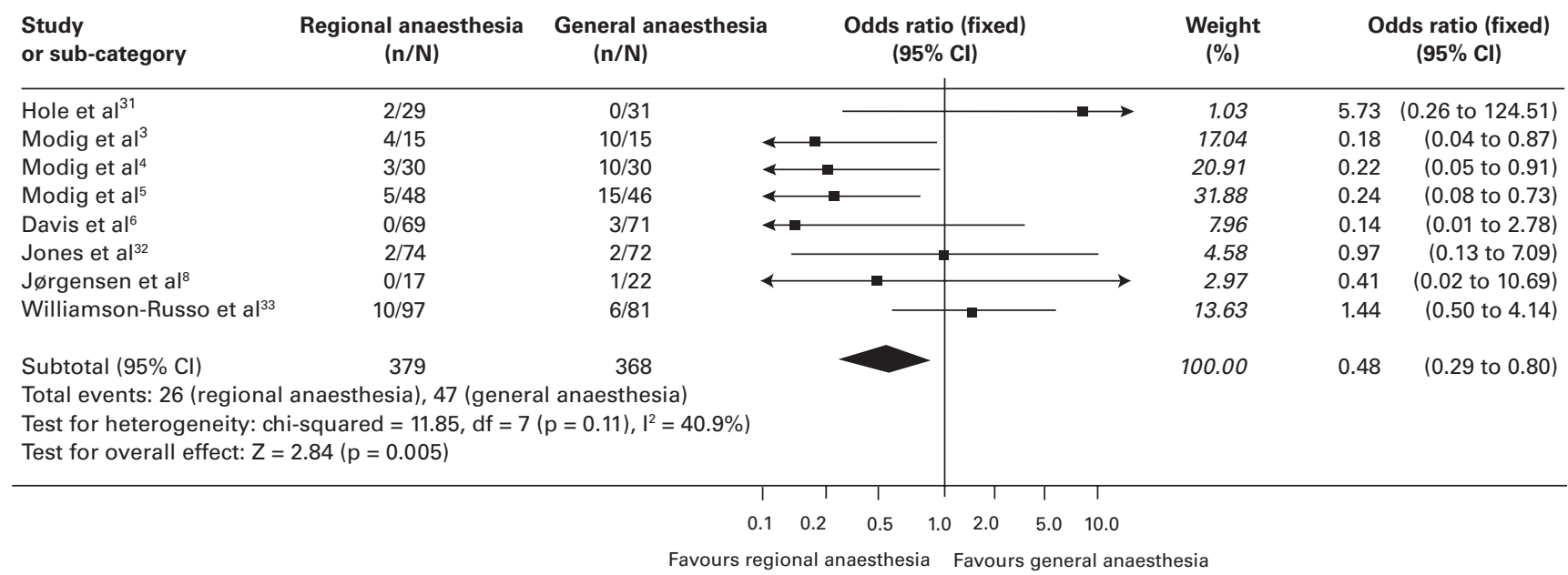

Fig. 4

Chart showing comparison of the number of patients with pulmonary embolism in the regional and general anaesthesia groups.

analysis indicated that regional anaesthesia significantly reduced the operating time for THR, a result which was consistent with that of other recent studies. ${ }^{35}$ However, this effect was not seen in patients undergoing TKR. The difference may relate to the use of a thigh tourniquet during TKR. The tourniquet gives an almost bloodless operating field which, in turn, may speed up the operation.

The pooled data showed a statistically significant decrease in blood loss in the regional anaesthesia group. However, some of the studies were performed 20 years ago and patients in the regional anaesthesia groups had a significantly lower blood pressure. ${ }^{3,4}$ A subgroup analysis of the eight THR studies, showed that there was no significant difference between the groups when this confounding factor was excluded. This is at odds with recent research by Mauermann et al. ${ }^{35}$ The explanation for this discrepancy may be that the latter included studies in which patients in the regional anaesthesia group had significant perioperative hypotension. Therefore we think the result from our subgroup analysis is more appropriate and conclusive. In the only study for which valid data about intra-operative blood loss could be extracted there was no significant difference between the two groups. ${ }^{27}$ They did not present the data in a form which could be included in the meta-analysis. Several other studies did not find any discernible difference between the two groups. ${ }^{8,18,36}$ This is easily explained. Bleeding after TKR, which is performed under tourniquet, occurs after the period of the anaesthetic effect, into surgical drains. Although we cannot refute the possibility that regional anaesthesia reduces blood loss in TKR, we contend that, if there is such an effect, it is probably very small. Data on the need for transfusion were reported in five studies. $^{6,21,30,32,34}$ We found that the use of regional anaesthesia reduced the risk of blood transfusion. The overall blood loss was not significantly different between the two methods of anaesthesia, but significant differences were found between the groups as to the need for transfusion. We believe that the reason for this may be that patients having regional anaesthesia for a THR are given a plasma expander more often than those who have general anaesthesia. Consequently, while general anaesthesia for THR would appear to increase the need for blood transfusion, patients who have regional anaesthesia either for THR or TKR require significantly greater amounts of colloid to maintain their intravascular volume in order to compensate for sympathetic vasodilatation, thereby apparently reducing the need for blood transfusions.

The prevention of thromboembolic disease is of concern to all orthopaedic surgeons. Our meta-analysis showed a protective effect of regional anaesthesia against thromboembolic disease (DVT and pulmonary embolism) in patients undergoing total joint replacement. A similar effect has been demonstrated by others. ${ }^{6,9}$ This finding was also consistent with the results published by Rodgers et $\mathrm{al}^{2}$ which included over 9500 patients. There are many possible reasons for this effect including altered coagulability, increased volume flow to the lower limbs, an improved ability to breathe without pain and a reduction in the surgical stress responses. ${ }^{4,37}$ However, most of the studies which favour regional anaesthesia were carried out on patients who did not have heparin prophylaxis. ${ }^{10}$ These findings must be viewed cautiously. A previous review ${ }^{38}$ showed that regional anaesthesia was inadequate as sole prophylaxis, although it may reduce the incidence of thromboembolic disease by $50 \% .^{39}$ However, a recent review showed that epidural anaesthesia without anticoagulants resulted in a low incidence of venous thromboembolism in patients undergoing THR. ${ }^{40}$ We suggest that on this basis regional anaesthesia, when used in conjunction with a prophylactic anticoagulant, will be more beneficial in decreasing the rate of thromboembolism, especially in those patients with risk factors such as varicose veins, 
malignancy and smoking. old age and the use of oral oestrogens. ${ }^{6}$

Our data have shown that the incidence of postoperative nausea and vomiting was significantly lower in the regional group than in the general anaesthesia group. Some authors have suggested that this is because regional anaesthesia provides significantly better post-operative analgesia, ${ }^{41}$ which leads to a lower consumption of opioids. However, the sample size was small and the impact of regional anaesthesia on post-operative nausea and vomiting was inconclusive.

In our meta-analysis, we failed to confirm that regional anaesthesia was associated with a reduced length of stay in hospital or reduced mortality.

Despite the relatively large number of patients studied, there were several limitations to our study. First, we limited our meta-analysis to articles in English. Although the effect of excluding non-English trials on the results of a metaanalysis is unclear, exclusion of such trials may have little effect on the summary effects of treatment and may actually give a more conservative estimate of the effect of treatment. ${ }^{42}$ Secondly, although the data were weighted by trial size, they were not weighted by the quality of the randomised controlled trials included nor were they assessed in a blinded fashion. We believe that the quality of the trials was generally similar, since all were randomised and controlled. We also used a random-effects model for metaanalysis, which assumed some heterogeneity between studies and was thus more stringent in assigning statistical significance than a fixed-effect model. Lastly, although these data represent most of the randomised evidence available, the CIs were wide for many outcomes and the summary estimates of effect (OR and standardised mean difference) should be interpreted with caution.

In conclusion, our data support the recent trend towards the increased use of regional anaesthesia. Furthermore, epidural anaesthesia/analgesia has been shown to improve the post-operative outcomes by relieving pain, reducing pulmonary complications, allowing early mobilisation and shortening the length of hospital stay. ${ }^{11,17,43}$

No benefits in any form have been received or will be received from a commercial party related directly or indirectly to the subject of this article.

\section{References}

1. No authors listed. Health and Human Services. Number of patients, number of procedures, average patient age, average length of stay of National Hospital Discharge Survey 1998-2005. American Academy of Orthopaedic Surgeons, 2008.

2. Rodgers A, Walker N, Schug $\mathbf{S}$, et al. Reduction of postoperative mortality and morbidity with epidural or spinal anaesthesia: results from overview of randomised trials. BMJ 2000;321:1493.

3. Modig J, Hjelmstedt A, Sahlstedt B, Maripuu E. Comparative influences of epidural and general anaesthesia on deep venous thrombosis and pulmonary embolism after total hip replacement. Acta Chir Scand 1981;147:125-30.

4. Modig J, Borg T, Karlstrom G, Maripuu E, Sahlstedt B. Thromboembolism after total hip replacement: role of epidural and general anesthesia. Anesth Analg 1983;62:174-80.

5. Modig J, Maripuu E, Sahlstedt B. Thromboembolism following total hip replacement: a prospective investigation of 94 patients with emphasis on the efficacy of lumbar epidural anesthesia in prophylaxis. Reg Anesth 1986;11:72-9.
6. Davis FM, Laurenson VG, Gillespie WJ, et al. Deep vein thrombosis after total hip replacement: a comparison between spinal and general anaesthesia. J Bone Joint Surg [Br] 1989;71-B:181-5.

7. Sharrock NE, Haas SB, Hargett MJ, et al. Effects of epidural anesthesia on the incidence of deep-vein thrombosis after total knee arthroplasty. J Bone Joint Surg [Am] 1991;73-A:502-6.

8. Jørgensen LN, Rasmussen LS, Nielsen PT, Leffers A, Albrecht-Beste E. Antithrombotic efficacy of continuous extradural analgesia after knee replacement. $\mathrm{Br} \mathrm{J}$ Anaesth 1991:66:8-12.

9. Nielsen PT, Jørgensen LN, Albrecht-Beste E, Leffers AM, Rasmussen LS. Lower thrombosis risk with epidural blockade in knee arthroplasty. Acta Orthop Scand 1990;61:29-31.

10. Schäfer M, Elke R, Young JR, Gancs P, Kindler CH. Safety of one-stage bilateral hip and knee arthroplasties under regional anaesthesia and routine anaesthetic monitoring. J Bone Joint Surg [Br] 2005;87-B:1134-9.

11. Moraca RJ, Sheldon DG, Thirlby RC. The role of epidural anesthesia and analgesia in surgical practice. Ann Surg 2003;238:663-73

12. Brueckner S, Reinke U, Roth-Isigkeit A, et al. Comparison of general and spinal anesthesia and their influence on hemostatic markers in patients undergoing total hip arthroplasty. J Clin Anesth 2003;15:433-40.

13. Planès A, Vochelle $\mathbf{N}$, Fagola $\mathbf{N}$, Feret $\mathbf{J}$, Bellaud $\mathbf{M}$. Prevention of deep vein thrombosis after total hip replacement: the effect of low-molecular-weight heparin with spinal and general anaesthesia. J Bone Joint Surg [Br] 1991;73-B:418-22.

14. Mitchell D, Friedman RJ, Baker JD 3rd. Prevention of thromboembolic disease following total knee arthroplasty: epidural versus general anesthesia. Clin Orthop 1991;269:109-12.

15. Moiniche S, Hjortso NC, Hansen BL, et al. The effect of balanced analgesia on early convalescence after major orthopaedic surgery. Acta Anaesthesiol Scand 1994;38:328-35

16. Gedney JA, Liu EH. Side-effects of epidural infusions of opioid bupivacaine mixtures. Anaesthesia 1998;53:1148-55.

17. Chu CP, Yap JC, Chen PP, Hung HH. Postoperative outcome in chinese patients having primary total knee arthroplasty under general anaesthesia/intravenous patient-controlled analgesia compared to spinal epidural anaesthesia/analgesia. Hong Kong Med J 2006;12:442-7.

18. Nielson WR, Gelb AW, Casey JE, et al. Long-term cognitive and social sequelae of general versus regional anesthesia during arthroplasty in the elderly. Anesthesiology 1990;73:1103-9.

19. Thorburn J, Louden JR, Vallance R. Spinal and general anaesthesia in total hip replacement: frequency of deep vein thrombosis. Br J Anaesth 1980;52:1117-21.

20. Davis FM. Anesthesia for hip surgery. Comparative studies of spinal anaesthesia and general anaesthesia for elective total hip arthroplasty and internal fixation of fractures of the femoral neck in the elderly. University of Otago, 1987 [MD Thesis].

21. Borghi B, Casati A, luorio S, et al. Frequency of hypotension and bradycardia during general anesthesia, epidural anesthesia, or integrated epidural-general anesthesia for total hip replacement. J Clin Anesth 2002;14:102-6.

22. Borghi B, Casati A, luorio $\mathbf{S}$, et al. Effect of different anesthesia techniques on red blood cell endogenous recovery in hip arthroplasty. J Clin Anesth 2005;17:96-101.

23. Davis FM, McDermott E, Hickton $\mathbf{C}$, et al. Influence of spinal and general anaesthesia on haemostasis during total hip arthroplasty. Br J Anaesth 1987;59:561-71.

24. Gonano C, Leitgeb U, Sitzwohl C, et al. Spinal versus general anesthesia for orthopedic surgery: anesthesia drug and supply costs. Anesth Analg 2006;102:524-9.

25. Lattermann R, Belohlavek G, Witmann S, et al. The anticatabolic effect of neuraxial blockade after hip surgery. Anesth Analg 2005;101:1202-8.

26. Kita T, Maki N, Song YS, et al. Caudal epidural anesthesia administered intraoperatively provides for effective postoperative analgesia after total hip arthroplasty. $J$ Clin Anesth 2007:19:204-8.

27. Kudoh A, Takase $\mathbf{H}$, Takazawa T. A comparison of anesthetic quality in propofolspinal anesthesia and propofol-fentanyl anesthesia for total knee arthroplasty in elderly patients. J Clin Anesth 2004;16:405-10.

28. Modig J, Karlstrom G. Intra- and post-operative blood loss and haemodynamics in total hip replacement when performed under lumbar epidural versus general anaesthesia. Eur J Anaesthesiol 1987:4:345-55.

29. Wulf H, Biscoping J, Beland B, et al. Ropivacaine epidural anesthesia and analgesia versus general anesthesia and intravenous patient-controlled analgesia with morphine in the perioperative management of hip replacement. Anesth Analg 1999;89:111-16

30. Donatelli F, Vavassori A, Bonfanti S, et al. Epidural anesthesia and analgesia decrease the postoperative incidence of insulin resistance in preoperative insulinresistance subjects only. Anesth Analg 2007;104:1587-93.

31. Hole A, Terjesen T, Breivik H. Epidural versus general anaesthesia for total hip arthroplasty in elderly patients. Acta Anaesthesiol Scand 1980;24:279-87. 
32. Jones MJ, Piggott SE, Vaughan RS, et al. Cognitive and functional competence after anaesthesia in patients aged over 60: controlled trial of general and regional anaesthesia for elective hip or knee replacement. BMJ 1990;300:1683-7.

33. Williams-Russo $\mathbf{P}$, Sharrock NE, Haas SB, et al. Randomized trial of epidural versus general anesthesia: outcomes after primary total knee replacement. Clin Orthop 1996;331:199-208

34. Keith I. Anaesthesia and blood loss in total hip replacement. Anaesthesia 1977;32:444-50.

35. Mauermann WJ, Shilling AM, Zuo Z. Comparison of neuraxial block versus general anesthesia for elective total hip replacement: a meta-analysis. Anesth Analg 2006;103:1018-25

36. Kohro S, Yamakage M, Arakawa J, et al. Surgical/tourniquet pain accelerates blood coagulability but not fibrinolysis. Br J Anaesth 1998;80:460-3.

37. Modig J, Borg T, Bagge L, Salden T. Role of extradural and of general anaesthesia in fibrinolysis and coagulation after total hip replacement. Br J Anaesth 1983;55:625-9.
38. Feller JA, Parkin JD, Phillips GW, et al. Prophylaxis against venous thrombosis after total hip arthroplasty. Aust N Z J Surg 1992;62:606-10.

39. Prins $\mathbf{M H}$, Hirsh J. A comparison of general anaesthesia and regional anaesthesia as a risk factor for deep vein thrombosis following hip surgery: a critical review. Thromb Haemost 1990;64:497-500.

40. Daniel J, Pradhan A, Pradhan C, et al. Multimodal thromboprophylaxis following primary hip arthroplasty: the role of adjuvant intermittent pneumatic calf compression. J Bone Joint Surg [Br] 2008;90-B:562-9.

41. Block BM, Liu SS, Rowlingson AJ, et al. Efficacy of postoperative epidural analgesia: a meta-analysis. JAMA 2003;290:2455-63.

42. Juni P, Holenstein F, Sterne J, Bartlett C, Egger M. Direction and impact of language bias in meta-analyses of controlled trials: empirical study. Int J Epidemiol 2002;31:115-23.

43. Ballantyne J, Carr D, de Ferranti S, et al. The comparative effects of postoperative analgesia therapies on pulmonary outcome: cumulative meta-analysis of randomized, controlled trials. Anesth Analg 1998;86:598-612. 